\title{
Making the governance of public bodies work: chair-chief executive relationships in practice
}

\section{David Heald and David Steel ${ }^{1}$}

The importation, over the past 30 years, of private sector governance into public bodies at arm'slength from government has brought greater focus on the relationship of part-time non-executive chairs and full-time chief executives. This paper explores this relationship in 14 UK bodies, based on in-depth interviews with chairs, chief executives and, as triangulation, audit committee chairs. The findings concern the negotiated differentiation of roles; the effects of the chief executive's separate authority as accounting officer in internal governance; the management of external stakeholders; and how crisis can affect roles and relationships. Improved processes of training and mentoring are proposed.

Keywords: Accounting Officer; chair-chief executive relationships; public bodies; public sector corporate governance; quangos.

'Public bodies' - understood as public sector organizations at arm's length from ministers - are an enduring feature of governments in many countries. Notwithstanding this institutional durability, their legitimacy is repeatedly challenged, leading for example in the United Kingdom to much rhetoric about 'bonfires of the quangos'. How much genuine substance attaches to these attacks is disputable; but the growth and practices of organizations at the fringes of government have generated a large literature (for example, Skelcher 1998; Flinders 2008).

Whereas the placing of government activities into arm's-length bodies has expanded internationally, country practices and terminology differ in important ways. A striking feature of public bodies in the UK is their heterogeneity in legal and organizational form, alongside a mixture of benign and malign motives for establishment and preservation. Linked to New Public Management pressures to make the public sector as alike the private sector as possible, the last 30 years have seen private sector corporate governance practices imported into UK public bodies and, to a lesser extent, into ministerial departments and their executive agencies. The design of these governance arrangements has incorporated from the private sector the theory of principal-agent relationships and made explicit provision for a (parttime) non-executive chair and a (full-time) chief executive.

\footnotetext{
${ }^{1}$ David Heald is Professor of Accountancy at the University of Aberdeen Business School, UK. David Steel is Honorary Senior Research Fellow at the University of Aberdeen and spent 10 years as an NHS chief executive.
} 
The research reported in this paper examines whether the practice of this relationship in nonministerial departments, non-departmental public bodies, public corporations, and companies limited by guarantee is consistent with the principal-agent assumptions that underlie their governance. Specifically it addresses the question of how chairs and chief executives differentiate their roles and the extent to which this depends on personal characteristics and experience rather than the policy context and operational substance of the organization; and whether there is a uniform pattern or whether this is negotiated explicitly or implicitly - contingent on circumstances and personal characteristics.

The paper is structured in the following way. Section 2 elucidates the principal-agent assumptions that underpin the position of public bodies within the governmental system, showing how that bears upon the respective roles of chair and chief executive and their relationship. Section 3 presents findings from an empirical UK study of chair-chief executive roles and relationships. Section 4 concludes with a discussion of the implications of these findings for policy and practice.

\section{The principal-agent perspective on the governance of public bodies}

The governance arrangements of public bodies are closely modelled on 'best practice' in the private sector, as developed through a series of reports starting with the Cadbury Report (1992). The private sector logic is clear and well-articulated, if a little shaken by governance failures after 2008. Principal-agent theory dominates theorizing: shareholders are the principal and management is the agent; their rational economic interests diverge due to asymmetric information, which generates problems of moral hazard and adverse selection. Management must be induced to behave in the interests of shareholders by means of incentive remuneration systems and board monitoring of executive performance. The presumed objective is to maximize shareholder wealth.

The part-time non-executive chair and non-executive directors form a majority in a unitary board, together with an audit committee chaired by a non-executive director, and are integral parts of the private corporate sector model. If these internal governance mechanisms fail, the company is vulnerable to the market discipline of takeover as part of external governance.

Importing these governance mechanisms into public bodies raises a number of important issues, some obvious, some more subtle (Cornforth 2005).

First, principal-agent theory is a convenient way to conceptualize 'vertical accountability' in the public sector. Principal-agent relationships are in series: public to parliament; parliament to minister; minister to board of the public body; and board to management. Bovens (2005) adds 'horizontal accountability' owed directly by public bodies to 'citizens, interest groups, panels'.

Whereas in the corporate private sector stakeholders other than shareholders are experienced as constraints, the power and legitimacy of non-government stakeholders in relation to public bodies can be 
highly uncertain. Tirole (1994) and Dixit (1997) characterize democratic government in principal-agent terms, emphasizing that a public organization having multiple principals provides greater room for management to pursue their own objectives. The inevitable result is lower-powered incentives for management (remuneration cannot be highly conditional on performance) and more emphasis on monitoring (as a substitute for incentives and because of wider obligations of accountability). There is a particular issue for public bodies because the corporate board model has spread across the public sector at the same time as the Accounting Officer (AO) line of personal accountability of the chief executive to parliament remains firmly in place (Treasury 2013, Chapter 3). There is a tendency to add further governance mechanisms on top of existing ones, without considering the extent to which they are substitutable or complementary, or whether the governance bundle is coherent (Ward et al. 2009).

Second, and accentuating the multiple principals point, public bodies lack the clear and wellspecified objective functions of private sector corporates. Instead of maximizing shareholder wealth, exactly what are their core objectives? These can often be described in the inspirational language of mission statements, yet they lack the operational specificity necessary to determine whether the public body should be judged as successful. What constitutes success is usually contestable, in part because different stakeholders will apply different criteria. Perceived (or proclaimed) success is likely to be claimed by many authors and revealed failure by none (Hood 2011). The formal justifications for establishing public bodies often include expectations of greater operational efficiency and of 'independence' that insulates decision-making from political intervention. How secure that depoliticization is can be uncertain. Such a context provides ample opportunity for blame-avoidance and blame-shifting tactics, not only by chairs and chief executives but also by ministers in sponsor departments whose terms of office are often short and unconnected to the business planning cycle of public bodies.

Third, in democratic regimes, the leverage derived from hierarchical power and funding relationships is rarely enough: public bodies have pressing needs for legitimacy. Placed outside the direct line of ministerial accountability to parliament, public bodies are often perceived to have accountability deficits; mechanisms of horizontal accountability (such as audit and inspection agencies and engagement with stakeholders) might compensate for deficits in vertical accountability (Schillemans 2011). As the external face of public bodies, chairs and chief executives are implicated in the process of constructing legitimacy.

Being public bodies in need of non-market legitimation, the political context changes recruitment to these roles. The representativeness (on various dimensions) of board members may figure prominently, the lack of which facilitates media and political attacks, including those motivated by other issues. This provides a counter-criterion to that of sectoral expertise and managerial experience/skills. Moreover, ministers (as principals) may wish to use the power of chair and non-executive appointments as a 
mechanism for reshaping or redirecting a public body. In contrast, chief executive posts in public bodies are usually filled by career professional managers, thereby distinguishing the background, skill sets and experience of chair and chief executive to a greater extent than in the corporate private sector. The complementarity and/or substitutability of the attributes of chair and chief executive therefore raise interesting questions. In some cases the nature of the activity of the public body will emphasize the distinction between governance (the board) and management of a specialized, professionalized activity (for example, grant awarding and regulatory approvals). In others, general business skills are relevant to both roles.

\section{Chair-chief executive relations in practice}

Despite the voluminous literature on 'quangos', the roles of chairs and chief executives within the actual operation of governance arrangements have been neglected. Previous research along similar lines, exclusively on National Health Service bodies, has been undertaken by Wall and Baddeley (1998) and Exworthy and Robinson (2001).

In light of the resources available and the timing window (October 2011 to March 2012), the following research design was established:

- Using official lists, public bodies were categorized as mainly regulatory, funding or service delivery

- Five UK public bodies were identified in each category, paying attention to whether responsibilities covered the UK, Great Britain, England and Wales, England or Scotland, to variations in organizational status, and sponsor department

- Formal letters were sent to the chair and chief executive, requesting individual face-to-face interviews of one hour, and asking the chair to contact the chair of the audit committee for the same facility so as to triangulate the views of the chair and chief executive

- Where cooperation was refused, either in entirety or by two persons, a substitute organization within the same category was identified

- The interviews followed a pre-circulated agenda of questions, and it was requested that the interviewees did not discuss this among themselves in advance. All interviews were recorded and professionally transcribed. Undertakings were given at the time of approach and at the interview that all research reporting would be on an anonymous basis.

Twelve of the original 15 organizations agreed to participate. Replacements were approached for one funding organization (successfully) and two service delivery organizations (one successfully, the other not). Table 1 provides information about the 14 public bodies at which interviews took place, without compromising anonymity (for example, not identifying the eight sponsor departments to which they related). 
No claims are made about the representativeness of the 14 study organizations. However, although varying in size, they are significant in terms of budgets, influence and public name-recognition. The researchers have gained further confidence in their findings from the responses of practitioners who attended six Knowledge Exchange and Transfer workshops held in the summer of 2013 and in January 2014.

The findings reported here are based on the perceptions of the interviewees. An important subsidiary objective of the project was to establish whether people at the highest level in public bodies are willing to talk openly about relationships in a way that would enrich evidence in future research from other sources, such as board papers and possibly direct observation of a smaller number of bodies (provided issues of access and generalisability could be overcome). The willingness of 39 interviewees to participate and agree to recording exceeded expectations.

Table 1: The interviewed public bodies

\begin{tabular}{|c|c|c|c|c|c|}
\hline Organisation & Function & Scope & Chair & CEO & $\begin{array}{c}\text { Audit } \\
\text { Committee } \\
\text { Chair (ACC) }\end{array}$ \\
\hline A & Regulatory & England \& Wales & $\sqrt{ }$ & $\sqrt{ }$ & $\sqrt{ }$ \\
\hline B & Regulatory & England \& Wales & $\sqrt{ }$ & $\sqrt{ }$ & $\sqrt{ }$ \\
\hline C & Regulatory & Great Britain & $\sqrt{ }$ & $\sqrt{ }$ & $\sqrt{ }$ \\
\hline D & Regulatory & England \& Wales & $\sqrt{ }$ & $\sqrt{ }$ & $\sqrt{ }$ \\
\hline E & Funding & England \& Wales & $\sqrt{ }$ & $\sqrt{ }$ & $\sqrt{ }$ \\
\hline F & Funding & England & & $\sqrt{ }$ & $\sqrt{ }$ \\
\hline G & Funding & United Kingdom & $\sqrt{ }$ & $\sqrt{ }$ & $\sqrt{ }$ \\
\hline H & Funding & England & $\sqrt{ }$ & $\sqrt{ }$ & $\sqrt{ }$ \\
\hline I & Funding & England & $\sqrt{ }$ & $\sqrt{ }$ & $\sqrt{ }$ \\
\hline J & Service Delivery & England & $\sqrt{ }$ & $\sqrt{ }$ & $\sqrt{ }$ \\
\hline $\mathbf{K}$ & Service Delivery & Great Britain & $\sqrt{ }$ & $\sqrt{ }$ & $\sqrt{ }$ \\
\hline $\mathbf{L}$ & Regulatory/ & Great Britain & & $\sqrt{ }$ & $\sqrt{ }$ \\
\hline $\mathbf{M}$ & Service Delivery & (United Kingdom)* & & & $\sqrt{ }$ \\
\hline $\mathbf{N}$ & Service Delivery & United Kingdom & $\sqrt{ }$ & $\sqrt{ }$ & $\sqrt{ }$ \\
\hline
\end{tabular}

Notes: $\sqrt{ }$ : interview completed and recorded

*: some functions extend to Northern Ireland

The reasons for this appeared to be:

- The timing of the approach, in relation to the quango cull and unprecedented budget reductions (Gash et al., 2010; Treasury, 2010; Flinders and Skelcher, 2011).

- Interviewees' interest in talking about their role. 
- The name-checking value of the grant-awarding body; and the undertaking of anonymity.

\section{Similarities with the Private Sector Model}

The terms in which respondents described the roles of chairs and chief executives, and how the relationship is managed internally (see next section), accord with normal practice in the private sector. The chair's role was defined as running the board and relating to ministers and the chairs of partner organizations, and the chief executive's role as running the organization and relating to civil servants and officers of partner organizations:

But, by and large, [the CEO] runs the business and I'm running the Board. [N: Chair]

In its simplest form, [the CEO] runs the organization on a day-to-day basis. My chief role is to be external ambassador of this organization and its critical friend. [The CEO] has by far the most contact with...officials. My main contact is with the minister. [C: Chair]

In other respects too, the findings of the fieldwork resonate with private sector practice. First, within this broad definition of roles, there is wide variation in the extent of the chair's involvement and in the actual division of responsibility. In some bodies the chief executive plays an enhanced role, usually linked to differential task knowledge: for example, where they have previously held a senior position within the sector and brought to the post pre-existing relationships with ministers, senior civil servants and/or leaders of sectoral organizations; or where the time the chair has available is limited as a result of holding multiple appointments.

On the other hand, when the chair has a high public profile prior to appointment, whether personal or political, their role tends to be enhanced, particularly in handling media enquiries and parliamentary business. Some very experienced chairs also stressed their role as mentor or critical friend to the chief executive, while accepting that there could be circumstances which require them to convey harsh truths and, in extremis, to ask them to resign:

The chair is there as a mentor, an encourager, a supporter of the chief executive... Of course, ultimately [the chair is] nominally the boss. There's a joke that when a chair wakes up in a morning, you ask yourself one question: 'Do I have to sack the chief executive today?' And if the answer's 'No', you go back to sleep. [H: Chair]

It's the ability of the chair to nourish, nurture and push along the chief executive, be very sensitive to the chief executive's daily travails and to be able almost intuitively to sense when the guy needs help because chief executives don't always ask for help. [D: Chair]

Second, crises potentially have an impact on the division of responsibility within any particular body. If the crisis is policy-focused or relates to a controversial decision taken by the chief executive, the chair is likely to be more prominent. A number of chairs saw their role as providing cover for the chief executive:

I have always seen the role of the chair as providing air cover to the [chief] executive. You've got the chief exec who's beavering away on the ground, trying to cut through the foliage and do whatever needs to be done. [H: ACC] 
If the crisis is related to organizational performance generally, it is a more open question as to who will lead and how they will divide up tasks, influenced for example by relative expertise (and thus confidence on the issues) and media skills. Crises were also said to accentuate the salience of the chairchief executive relationship and the degree to which the board as a whole becomes more involved (the norm) or is marginalized:

As soon as an organization starts getting into real difficulty...you then find the non-execs become more quasi-executive for a period of time, until you re-establish control, re-establish the capability of the executive [team] and then you back off. [M: Chair]

\section{Managing internal governance}

A recurrent theme was that a good relationship depends upon there being 'no surprises'. For this to happen at least two prerequisites were stressed. First, there needs to be clarity and mutual understanding particularly between the chair and chief executive but also involving other key players such as nonexecutive directors and government officials - on who leads on particular issues and on the sharing of information. On this latter aspect there are situations where such sharing needs to occur before a decision is taken so that there is an opportunity for discussion and the giving of advice. In others it needs to happen only before a decision is widely promulgated so that neither party is wrong-footed. In the complex and fast-moving world inhabited by many public bodies such an understanding also requires a high degree of trust, transparency and openness between chairs and chief executives:

Clarity of respective roles...and mutual respect. And a recognition of different skill sets because my skill set and [the CEO's] are completely different. But we recognize each other's respective strength. [C: Chair]

I think there's a really important bit about being clear early doors about my job/your job...about having a reasonably clear understanding as to at least if not precisely where the line is, then what the no man's land is where you could both tread. [I: CEO]

In this context personal chemistry is an important factor, helping to resolve difficulties or, when it is absent, exacerbating them. The problem, however, is to predict in advance how such chemistry will play out in practice. Clearly, it helps if the chair and chief executive have previous knowledge of each other and experience of working together. That said, one respondent warned against the risk of them being too close, which could imperil relations between the chair and non-executive directors on the one hand and between the chief executive and the management team on the other.

I think a lot of it's personality. It really is. You can codify things but unless you've got a good working relationship... and you've got to be close but not too close. [E: Chair]

Well I'd say the critical factor is the personal chemistry...And I think the role of the Chair and the Chief Executive is for it to be clear that their relationship is good enough and close enough that it doesn't either fuel mistrust or contempt for the Board from the executive [team] or vice versa. [A: CEO]

One factor that did seem to help was experience, past or current, of the 'other' role. In a number of cases, chairs who had previously been a chief executive in another organization seemed to have a particularly good understanding of the line which a non-executive chair should not cross. A number of 
chief executives rated highly the experience they had gained from service as a non-executive elsewhere, particularly in the understanding it gave them of non-executive perspectives:

It's given me an insight into when to be hands-on and when to be hands-off. So, I think it's having the ability to take a broader view and to know when to really...drill down. [H: CEO]

Given the importance all respondents attached to these considerations, it is surprising that little attention is paid in public appointments to 'fit' between chair and chief executive. This omission carries high risk, given the disruption and costs involved in replacing a chief executive or chair when relationships break down. Fit is difficult to achieve, particularly in a political context in which stress is placed on openness and fairness in appointments to both non-executive and executive roles. The principal-agent setting within which their respective roles are embedded differs in important ways from that of the corporate private sector; this was stressed by respondents with experience of both sectors. It is reinforced by the greater diversity in the public sector in the background and experience of chairs, which can lead to greater dissimilarity from the chief executive than would occur in the private sector.

Few respondents said that they had sought external support in the process of defining roles or of reviewing them following a change in one of the officeholders, and in putting whatever is agreed into practice. Moreover, while appraisal of chief executives by their chair was universal, sometimes with input also from the sponsor department, only a few of the chairs interviewed had put in place arrangements for their own appraisal, for example through a 360 degree process (although some are subject to departmental review of performance).

\section{Special Public Sector Factors}

The interviews revealed two special factors that affect the operation of the relationship in public bodies and stand in sharp contrast to the private sector:

- The personal financial accountability of the chief executive as AO.

- The appointment of the chair by ministers rather than by the board. They also highlighted the significance of the external political context in which public bodies operate.

All respondents stressed the importance of AO status, under which the chief executive is personally accountable to parliament for the propriety and regularity of spending and also for value-for-money in its use. This gives chief executives an authority that is independent of the board that appointed them and to which they are accountable in other respects. Indeed, greater significance was attached to this than to the question of whether the chief executive formally sits on the board as an executive director. This source of authority for the chief executive is underpinned by the power of the AO of the sponsor department (normally the Permanent Secretary) to withdraw AO status, thereby effectively terminating the chief executive's appointment. In some instances this was reinforced by the appointment being made by the department (with input from the board rather than the other way round): 
There are areas where the council or board of any public body cannot direct the chief executive to take a course of action if [the CEO] thinks it's inappropriate with the requirements... as Accounting Officer, absolutely black and white. [G: ACC]

Very, very rarely exercised but yes, [being the AO] can be hugely important. [K: CEO]

The other special factor flows from ministerial appointment of the chair. A number of respondents commented that their involvement in the organization's affairs was closer and that they had a higher public profile than they had experienced as a non-executive chair in the private sector because this is what ministers expect. Frequently, chairs are contracted to work for three days a week, a significantly greater time commitment than is normal in the private sector and one which some of those interviewed felt ran the risk of jeopardizing their non-executive status:

Well one of the oddities about government and it's different I think to the private sector is that ministers expect to speak to the chair in arm 's-length bodies, at a level of detail which is probably beyond what a non-executive chair would normally know. [H: ACC]

My instinct is three days a week is too much for an effective chair...it causes the role of the chair to blur into what is the responsibility of the chief Executive. [A: ACC]

These factors illustrate the very different context within which the chairs and chief executives of public bodies operate, compared to that of their private sector counterparts. The public leadership role, split between political and managerial strands, is difficult and nuanced (Pollitt 2003). The governance bundle includes formal mechanisms that are ill-fitting: the supremacy of the board (to which the chief executive reports and which has powers of removal); and the line of accountability of the chief executive to the AO of the sponsor department. The existence of twin principals creates vulnerability, especially when there is a change of government, but also through frequent ministerial turnover during the life of governments. In addition to these formal mechanisms of vertical accountability, the nature of the activities of public bodies means that the discharge of more informal mechanisms of horizontal accountability to various stakeholders will have feedback effects on legitimacy and effectiveness.

\section{Managing external stakeholders}

In the private sector, chairs, boards and chief executives can take for granted that the wishes of the shareholders (principal) focus exclusively on their financial returns, even if there are some differences in timescales over which financial performance should be assessed. High levels of remuneration for board and management are held to be justified so that the misalignment between the interests of principal and agent are narrowed.

In the context of public bodies, the identity of the principal - assumed here to be the minister currently in office - can be disputed. Other stakeholders might claim that the principal is parliament (which passed legislation to set up the body and annually votes funds) or 'the public' (a collective that is difficult to define). Turnover in sponsor departments is rapid, at both cabinet and junior minister levels the latter often being the main point of contact - and often bears little or no relation to job performance. 
There can be tension between what the current minister expects and the public body's interpretation of its statutory responsibilities. Moreover, some ministers (or their specialist advisers) may have principled objections to the existence or functions of a public body they sponsor: for example, holding a view that delivery should be by a private sector organization or that its regulatory activity is counter-productive.

A recurrent fear on the part of the interviewed chairs and chief executives was of being excluded from decisions fundamental to their operations or even existence, without having access:

As a chief executive what used to infuriate me was when ministers took daft decisions because they were getting duff advice... and you didn't even know what the civil servants were saying to them. [E: CEO]

[the public body] occupies that middle ground between the sector...it's an ambassador at court for the sector...this policy was pretty high-level and...the implications were not necessarily apparent to the policymakers, the ministers and government...There was a policy just announced with no thought given as to what it actually meant, or understanding of the [public body's] activities. [H: ACC]

Post-2010 retrenchments and job turnover in sponsor departments had often intensified such fears. Most respondents reported that these developments had damaged the ability of sponsor departments - policy divisions as well as sponsor divisions - to undertake the part of 'strategy' that belonged to them:

There's been a sea change in the amount of contact between us and [sponsor department] under this administration...the [sponsor department] seems to us to be in complete meltdown organizationally...to have a combination of the turnover, reduction in numbers of staff, loss of corporate memory. [A: Chair]

Now there are fewer of them there, I think we are seeing a more appropriate level of engagement than in the old days when there were lots of them, far too many of them, and they were trying to justify their existence and they were all over us...they want to move to what they describe as a sort of risk-based relationship. [J: CEO

While this might create opportunities for the boards of some public bodies to annex these matters, there remained concern that decisions would be taken elsewhere, perhaps in the Treasury or Cabinet Office, without a proper understanding of the issues. Interestingly, this is where having a 'big hitter' as chair was seen as a distinct advantage: examples included the ability to talk personally to ministers in the corridors of Westminster.

Chairs and chief executives experience the tension between vertical and horizontal accountability. They are embedded in a principal-agent model which emphasizes vertical accountability, yet the organization that they lead has to sustain its own legitimacy among a more diverse group of external stakeholders than would surround a private sector corporate. There might be little agreement on what constitutes 'success', with the minister always holding the power of abolition or resource starvation. Some chairs see part of their role as being ambassadorial, developing and maintaining external support for their public body and its mission. This legitimation role can sit uneasily alongside their governance role, which pertains to organizational performance. 


\section{Implications for policy and practice}

The findings of this study show that the relationship between the chair and chief executive of public bodies broadly accords with the imported model from the private sector. The fieldwork underlined the centrality of the chair-chief executive relationship in providing effective internal governance, managing external relationships (both those of vertical and horizontal accountability), sustaining mandated performance, and securing legitimacy.

However, its operation is affected significantly by public sector-specific factors and, within this framework, there is considerable role variation reflecting the personal characteristics and experience of specific individuals. Generally most relationships were reported to be working well, reflecting effective personal interactions and accommodations. In some cases there was blurring of roles but chair and chief executive are not substitutable titles. Whereas some interviewees had experience of both roles, others did not appear to be suited for the other role.

Within the context of open and fair appointments, greater attention should be paid when appointing either a chair or chief executive to 'fit' in terms of experience, personality and style. Succession planning also needs to be improved, for example to avoid the departure of chair and chief executive at the same time.

Diversity in the size, functions and political salience of different public bodies makes it unrealistic to strive for standardization. However, the variation in practice regarding the remunerated time commitment of chairs in this study was so great that further consideration should be given to what is expected. There are two alternatives: either to reassert the principle that chairs should remain nonexecutive; or to change either the status of the chair or of the public body.

Given ministerial and parliamentary expectations of chairs, the level of media interest in many public bodies and the high rate of turnover among chief executives, the appropriateness of modelling the chair's role on that of a non-executive Chair in the private sector might be questioned in particular cases. This might suggest appointing an executive chair of the public body and no separate chief executive, though the general undesirability of such a concentration of power in the private sector has been highlighted by Cadbury (1992) and in subsequent versions of the UK Corporate Governance Code (for example, Financial Reporting Council 2014). Alternatively, the arm's-length public body might be abolished and its functions pulled back into the ministerial department, either as a directorate or as an executive agency. This has happened recently in cases where ministers are under constant pressure to respond in parliament and the media on operational issues and/or wish to retain all policy-making powers themselves and to delegate only the implementation of their decisions. 
Where the present model is continued, greater support should be provided whenever a new appointment is made and when times are difficult, in terms of both training in relationship behaviours and professional mentoring. There would be merit in designating a senior independent director in each board to act as an intermediary/spokesperson for the rest of the board, especially the non-executive directors, and as a critical friend and sounding board to the chair and sometimes to the chief executive.

Many public bodies operate in politically sensitive arenas, although what is sensitive is frequently not stable over time. Claims to independence are then countered by allegations of unaccountability, on the basis that their leaders are not elected. The formal principal-agent relationship of vertical accountability (board to minister) has to accommodate the horizontal accountability claims of the public body's other stakeholders, which in some cases have the capacity to severely damage its legitimacy. Holding chairs and chief executives to account is conditioned by the specific public sector context of the former being ministerial appointments and the latter exercising AO responsibilities. Chairs and chief executives therefore have to negotiate such ambiguities in contexts where criteria of organizational success and failure are contestable and where ministers hold the power to abolish or dismember the public body.

\section{Acknowledgements}

The authors gratefully acknowledge a grant from the British Academy (SG10591) and an award from the University of Aberdeen Knowledge Exchange and Transfer Fund.

\section{References}

Bovens, M. (2005), Public accountability. In Ferlie, E., Lynn, L.E. Jr. and Pollitt, C. (Eds) The Oxford Handbook of Public Management (Oxford, Oxford University Press), pp. 182-208.

Cadbury Report (1992), The Financial Aspects of Corporate Governance (London, Financial Reporting Council). Cornforth, C. (2005), The Governance of Public and Non-Profit Organizations (London, Routledge).

Dixit, A. (1997), Power of incentives in private versus public organizations. American Economic Review, 87, 2, pp. 378-382.

Exworthy, M. and Robinson, R. (2001), Two at the top: relations between Chairs and Chief Executives in the NHS. Health Services Management Research, 14, 2, 82-91.

Financial Reporting Council (2014), UK Corporate Governance Code (London, Financial Reporting Council).

Flinders, M. (2008), Delegated Governance and the British State: Walking without Order (Oxford, Oxford University Press).

Flinders, M. and Skelcher, C. (2012), Shrinking the quango state: five challenges in reforming quangos. Public Money \& Management, 32, 5, pp. 327-334.

Gash, T., Magee, I., Rutter, J. and Smith, N. (2010), Read before Burning: Arm's Length Government for a New Administration (London, Institute for Government).

Hood, C. (2011), The Blame Game: Spin, Bureaucracy and Self-Preservation in Government (Princeton NJ, Princeton University Press).

Pollitt, C. (2003), The Essential Public Manager (Maidenhead, Open University Press).

Skelcher, C. (1998), The Appointed State: Quasi-Governmental Organisations and Democracy (Buckingham, Open University Press).

Schillemans, T. (2011), Does horizontal accountability work?: evaluating potential remedies for the accountability deficit of agencies. Administration \& Society, 43, 4, 387-416.

Tirole, J. (1994), The internal organization of government. Oxford Economic Papers, 46, 1, 1-29. 
Treasury (2010), Reforming Arm's Length Bodies (London, HM Treasury).

Treasury (2013), Managing Public Money (London, HM Treasury).

Wall A. and Baddeley S. (1998), Chair-Chief Executive relationships in the National Health Service. In Coulson, A. (Ed.) Trust and Contracts (Bristol, Policy Press), pp. 79-94.

Ward, A.J., Brown, J.A. and Rodriguez, D. (2009), Governance bundles, firm performance, and the substitutability and complementarily of governance mechanisms. Corporate Governance: An International Review, 17, 5, 646-660.

To cite this document:

David Heald and David Heald (2015), 'Making the governance of public bodies work: chair-chief executive relationships in practice', Public Money \& Management, Vol. 35, No. 4, pp. 257-64.

Permanent link to this document: DOI $\underline{10.1080 / 09540962.2015 .1047266}$ 